\title{
Improving the Quality of Care in Children with Juvenile Idiopathic Arthritis: A Step in the Right Direction
}
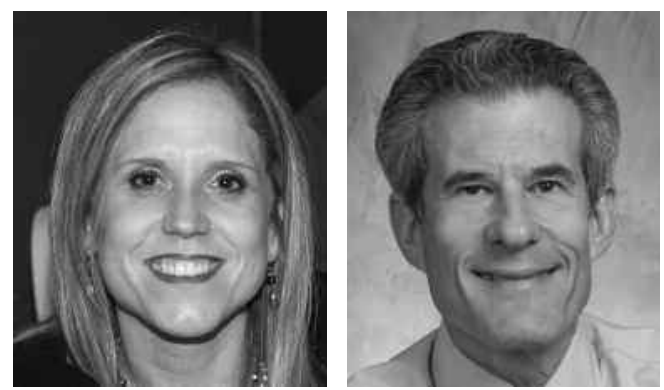

Juvenile idiopathic arthritis (JIA) is heterogeneous in both its clinical presentation and etiology 1,2 . JIA can result in permanent physical disability due to joint damage, while additional morbidity can be related to its treatment and to effects on growth and development. Children with inadequately treated or recalcitrant JIA may have chronic pain, mood disturbances, and difficulty with peer relationships, school performance, and attainment of educational and vocational goals $3,4,5,6,7,8$. Improved health related quality of life (HRQOL) and physical function are increasingly recognized as key treatment goals because of the influence of this illness on all aspects of a child's life ${ }^{9}$. Accurate evaluation of this multidimensional and heterogeneous disease is challenging, but crucial to improve the quality of care and outcomes in JIA.

Over the last decade there has been an increasing commitment to the assessment and improvement of quality of care following the report of The Institute of Medicine (IOM) Committee on Quality of Healthcare in America, "To Err is Human"10. The American College of Rheumatology (ACR) and American Board of Pediatrics have charged Pediatric Rheumatology with developing quality measures $(\mathrm{QM})$ for JIA. The initial work of this group included use of an online Delphi survey technique with participation from physicians, advanced practice nurses, and parents of children with JIA for the selection process of QM. In 2008, preliminary QM were published ${ }^{11}$. A nominal group technique was used to reach consensus on the proposed set of $\mathrm{QM}$ for the process of care. These include 4 broad domains: disease control, safety monitoring, access and relationship (patient/family satisfaction with healthcare) ${ }^{12}$. Within several of the QM, the use of validated, reliable, age-appropriate tools for measurement of pain, HRQOL, functional ability, self-efficacy, and patient/ parent satisfaction is proposed. A collaborative network, "Pediatric Rheumatology Care and Outcomes Improvement Network (PR-COIN)," has recently been established to develop and evaluate specific disease management strategies to improve the care of children with JIA and to determine how best to incorporate these strategies into clinical practice.
In this issue of The Journal, Filocamo, et al describe the Juvenile Arthritis Multidimensional Assessment Report (JAMAR), an instrument for assessment of children with JIA for use in standard clinical care ${ }^{13}$. The authors proposed that this report may help enhance the quality of care of children with JIA by addressing "efficiency" and "efficacy," two of the quality domains of the "STEEEP" acronym outlined by the IOM (safe, timely, effective, efficient, equitable, patient-centered $)^{14}$. One of the novel aspects of this tool is the inclusion of patient-reported outcomes (PRO), in a single tool including morning stiffness, medication side effects, self-report of articular symptoms, and patient satisfaction rating ${ }^{13}$. The inclusion of PRO is important to improve quality of care as these are part of the "patient-centered care" domain of quality outlined by the IOM.

Patient-specific indices offer the advantage of identifying salient issues for each patient and are more likely to focus medical attention on the relevant issues; however, they also present unique challenges to ensure the item/measure is reliable, valid, and provides useful information. Without standardization of the items, the response scales do not have the same meaning for each patient. This can make it difficult to understand the numeric meaning of a score. Second, using the data beyond intraindividual comparison is problematic ${ }^{15}$. Further studies are needed to improve our understanding of how to interpret the numeric scores of patient-specific indices at both the individual and group level.

The JAMAR contains two measurement tools, the Juvenile Arthritis Functionality Scale (JAFS) ${ }^{16}$ and the Pediatric Rheumatology Quality of Life Scale ${ }^{17}$, which were developed only recently. For both tools, initial validation studies have been reported. Although research on quality of care in pediatric rheumatology is in its infancy, there has been a longstanding focus on the measurement and reporting of disease outcome, HRQOL, and functional outcome in JIA. There are many tools available to measure clinical response (i.e., ACR Pediatric $30^{18}$ ), functional status (i.e., $\mathrm{CHAQ}^{19}$ ), and quality of life (PedsQL ${ }^{\mathrm{TM} 20}$, Child

See A new approach to clinical care of JIA, page 938 
Health Questionnaire ${ }^{21}, \mathrm{JAQQ}^{22}$ ). In addition, several of these instruments have been validated and are more widely used both in clinical and research settings. It would seem rational to use these existing tools both in clinical care and research to allow for comparison between patient groups.

The potential use of a multidimensional report as a surrogate for a clinical encounter is intriguing. It is interesting to consider how we assess our individual patient's status and the factors that guide our management decisions. Studies comparing the decision-making process after a clinical encounter versus using the results of a multidimensional report, such as the JAMAR, would be of interest.

In summary, JIA is a heterogeneous and multidimensional disease. Improving the process of quality care delivery is a topical issue. The development of the JAMAR importantly illustrates the breadth and potential content in a multidimensional report. Future work should be focused on refining and validating the existing measures used in JIA both in clinical practice and in the research setting. Particular attention needs to be focused on interpreting scores/summary scales for PRO. An international consensus on disease activity measures, functional assessment, assessment of HRQOL, and PRO is key to advancing work in this area. In order to evaluate the QM for the process of care, universal agreement on measures to be used will facilitate implementation of QM into routine clinical practice for clinicians. The aim should be to minimize duplication of work and focus on implementation of $\mathrm{QM}$ to improve the process of care, then to evaluate these tools and refine them in the plan-do-study-act rapid cycles of improvement ${ }^{23}$.

ROBERTA BERARD, MD, MSc, FRCPC, Assistant Professor of Pediatrics, University of Western Ontario, London, Ontario;

RONALD M. LAXER, MDCM, FRCPC,

Division of Rheumatology,

The Hospital for Sick Children,

Professor of Paediatrics and Medicine,

University of Toronto,

Toronto, Ontario, Canada

Address correspondence to Dr. Laxer.E-mail: ronald.laxer@sickkids.ca

\section{REFERENCES}

1. Ravelli A, Martini A. Juvenile idiopathic arthritis. Lancet 2007:369:767-78.

2. Martini A. Lovell DJ. Juvenile idiopathic arthritis: state of the art and future perspectives. Ann Rheum Dis 2010:69:1260-3.

3. Packham JC, Hall MA. Long-term follow-up of 246 adults with juvenile idiopathic arthritis: education and employment. Rheumatology 2002;41:1436-9.

4. Packham JC, Hall MA. Long-term follow-up of 246 adults with juvenile idiopathic arthritis: functional outcome. Rheumatology 2002:41:1428-35.

5. Packham JC, Hall MA, Pimm TJ. Long-term follow-up of 246 adults with juvenile idiopathic arthritis: predictive factors for mood and pain. Rheumatology 2002;41:1444-9.
6. Foster HE, Marshall N, Myers A, Dunkley P, Griffiths ID. Outcome in adults with juvenile idiopathic arthritis: a quality of life study. Arthritis Rheum 2003;48:767-75.

7. Packham JC, Hall MC. Long-term follow-up of 246 adults with juvenile idiopathic arthritis: social function, relationships and sexual activity. Rheumatology 2002;41:1440-3.

8. Minden K, Niewerth M, Listing J, Biedermann T, Bollow M, Schöntube M, et al. Long-term outcome in patients with juvenile idiopathic arthritis. Arthritis Rheum 2002;46:2392-401.

9. Brunner HI, Giannini EH. Health-related quality of life in children with rheumatic diseases. Current Opin Rheumatol 2003;15:602-12.

10. Kohn LT, Corrigan JM, Donaldson MS, editors. To err is human. Building a safer health system. Committee on Quality of Health Care in America. Washington: Institute of Medicine; National Academy Press; 1999.

11. Passo MH, Taylor J. Quality improvement in pediatric rheumatology: what do we need to do? Curr Opin Rheumatol 2008;20:625-30.

12. Lovell DJ, Passo MH, Beukelman T, Bowyer SL, Gottlieb BS, Henrickson M, et al. Measuring process of arthritis care. A proposed set of quality measures for the process of care in juvenile idiopathic arthritis. Arthritis Care Res 2011;63:10-6.

13. Filocamo G, Consolaro A, Schiappapietra B, Dalprà S, Lattanzi B, Magni-Manzoni S, et al. A new approach to clinical care of juvenile idiopathic arthritis: the Juvenile Arthritis Multidimensional Assessment Report. J Rheumatol 2011;38:938-53.

14. Institute of Medicine (US). Committee on Quality of Healthcare in America. Netlibrary Inc. Crossing the quality chasm: a new health system for the 21 st century. Washington, DC: Institute of Medicine: 2001.

15. Jolles BM, Buchbinder R, Beaton DE. A study compared nine patient-specific indices for musculoskeletal disorders. J Clin Epidemiol 2005;58:791-801.

16. Filocamo G, Sztajnbok F, Cespedes-Cruz A, Magni-Manzoni S, Pistorio A, Viola S, et al. Development and validation of a new short and simple measure of physical function for juvenile idiopathic arthritis. Arthritis Rheum 2007;57:913-20.

17. Filocamo G, Schiappapietra B, Bertamino M, Pistorio A, Ruperto N, Magni-Manzoni S, et al. A new short and simple health-related quality of life measurement for paediatric rheumatic diseases: initial validation in juvenile idiopathic arthritis. Rheumatology 2010;49:1272-80.

18. Giannini EH, Ruperto N, Ravelli A, Lovell DJ, Felson DT, Martini A. Preliminary definition of improvement in juvenile arthritis. Arthritis Rheum 1997;40:1202-9.

19. Singh G, Athreya BH, Fries JF, Goldsmith DP. Measurement of health status in children with juvenile rheumatoid arthritis. Arthritis Rheum 1994;37:1761-9.

20. Varni JW, Seid M, Smith Knight T, Burwinkle T, Brown J, Szer IS. The PedsQL in pediatric rheumatology: reliability, validity, and responsiveness of the Pediatric Quality of Life Inventory Generic Core Scales and Rheumatology Module. Arthritis Rheum 2002;46:714-25.

21. Landgraf JM, Abetz L, Ware JE. The CHQ user's manual. Boston: The Health Institute, New England Medical Center; 1996.

22. Duffy CM, Arsenault L, Duffy KN, Paquin JD, Strawczynski H. The Juvenile Arthritis Quality of Life Questionnaire development of a new responsive index for juvenile rheumatoid arthritis and juvenile spondyloarthritides. J Rheumatol 1997;24:738-46.

23. Langley GJ, Nolan KM, Norman CL, Provost LP, Nolan TW. The improvement guide: A practical approach to enhancing organizational performance. 2nd ed. San Francisco: Jossey-Bass Business \& Management Series; 2009.

J Rheumatol 2011;38:789-90; doi:10.3899/jrheum.110047 